\title{
The Way Forward: Reviewing an Interior Design Curriculum in the United Arab Emirates
}

-Isra Abu Zayed: Instructor at American University in the Emirates, Dubai, United Arab Emirates.

Solomon Arulraj David: Associate Professor of Education at the British University, Dubai, United Arab Emirates.

ABSTRACT: According to Dubai's Design and Fashion Council's (DDFC) Design Outlook Report 2016, the MENA region will require approximately 30,000 design graduates by the year 2019. This number is nine times the existing amount of design graduations currently produced annually (DDFC 2016). Therefore, the design education industry is continually growing and becoming very competitive. In the UAE, there are currently 11 institutes, which deliver a bachelor's degree in interior design. The aim of this paper is to bring forth recommendations to innovate and enhance an existing interior design program at a leading university in Dubai to set it apart from the competition. Utilizing a positivists (realism) approach to be able to determine the necessary reform required for the interior design program through the content analysis of a) relevant literature review, $b$ ) review and analysis of two program accreditation bodies, and c) reviewing two of the top five programs of interior design. An analysis of the findings was formed followed by a comparison to the existing interior design program at the selected university then resulted in three conclusions: 1. Improvement of the learning environment and the collaborative project work both within the institution and internationally. 2. Incorporate effective teaching methodology to enhance the student's visualization skills through converging and assimilating teaching methodologies. 3. Additional specialization courses to increase the percentage of design course output in the curriculum while additionally incorporating sustainable design within interior design program.

Key words: Interior design, Innovative curriculum, Curriculum review, Curriculum design, United Arab Emirates.

\section{Introduction}

Interior design is a practice, which has existed from the very beginning of human existence. It has been examined by anthropologists as means of understanding human development and culture. Humankind's advancement has always been paralleled into their built environment, allowing interiors to be a direct reflection of Their time (Association of Professional Interior Designers, 2017). During the ancient Egyptian era's interiors of the pharos's tombs were a direct reflection of the cultural practices of their time. Allowing us today, to better understand the people of that time. Similarly, reflections and studies are made when looking at every period, through interior spaces, their glorification and art, one can begin to better understand the people of that time.

Interior design as an industry is one that has only recently developed into a professional career. Over the last century, interior design has become established from a career, minimally understood, to one that is now a household necessity (American Society of Interior Designers, 2016). With this growth in the industry, a largescale educational opportunity has risen to prepare graduates for this new industry along with the special set of

Vol. 1, No. 2, pp. 71-82

Correspon

Funding: This study received no sp financial support.

Received: 13 March 2018

Revised: 26 October 2018

Accepted. 28 November 2018

() 2018 by the authors; licensee Academic 71 
skills required for it. Interior design is a difficult career to define, falling on the fine line between interior decorating practices and architectural ones.

The United Arab Emirates (UAE) and Dubai specifically are one of the leading cities in the arts and design profession. According to Dubai's Design and Fashion Council (DDFC) their Design Outlook Report, the MENA region will require approximate 30,000 design graduates by the year 2019. This number being nine times the existing amount of design graduations currently produced annually (2016). Therefore, the design educational industry is one, which is continually growing and becoming very competitive. In the UAE, there are currently 11 institutes, which deliver a bachelor's degree in interior design. Additionally of all the countries in the Middle East, UAE is ranked at the fourth country in which young graduate aspire to study. Allowing the UAE to position itself as the new academic destination in the Middle East (Dubai Institute of Design and Innovation, 2017). The aim of this paper is to bring form recommendations and reform to the existing Interior Design program curriculum at a leading university. In order to present a curriculum which is innovative and can set itself apart from the other programs offered across the region. The program will aid in the development of the university during a time in which the design industry is expected to grow tremendously.

\section{Methodology}

This research will look at the existing interior design specialization program. Studying the program structure, course CLOs and the overall PLOs in order to determine the currently standing of the specializations. Through literature review of Interior Design teaching methodology and program innovation as well as benchmarking the program with international and national interior design accreditation bodies. Utilizing a positivists (realism) approach to be able to determine the necessary reform required for the interior design program through the content analysis of a) relevant literature review, b) Review and analysis of two program accreditation bodies, and c) reviewing two of the top five programs of interior design. From this, appropriate recommendations can be made in order to fulfil the changes needed in order for the program's standard to be developed and gain its place in the growing design education industry in the UAE.

\section{Literature Review \\ 3.1. Creativity}

The state of the learning environment has a significant impact on that of the student body. Therefore, when considering an interior design program, it is vital to establish an understanding of the environmental impacts, which the institute and educational process can have on the student body. According to the study titled _Creativity and Empowerment' although creativity and empowerments are somewhat loose terms, with no rigid definition, it is believed that freedom of choice can lead to a more confident and optimistic person. When freedom of choice is offered to a person they can develop skills associated with courage and imagination, and through this a curiosity can be developed with leads to a more empowered person(Velthouse, 1990).

According to Tadmor et al, past research has shown the benefits of the multicultural experience on the output. It has been noted through the research that multiculturalism and diversity can enhance the creativity and the output of a given task. Therefore, the greater the diversity of teams and their varied experiences the stronger the creative content produced. This then highlights the importance of the diverse influence on individual's creativity (2012). In the research, Improving Memory through Creativity, the benefits of creativity are witnessed through the application of a creative program on older adults, some of which are facing diseases such as Alzheimer's and dementia. Through the evidence-based perspective, the resource shared the benefits of the creative program on the elderly subjects and the noticeable improvement of their memory through the creative capacity.

Creativity and the creative personality are sometimes seen as a divergence of thinking from the norm. Wallace (1986) attempted to frame the creative personality as a detachment of the socially expected. Stating the creativity bring together_passion and decorum' and therefore must be enhanced through the educational process. Educators must provide environments in which creativity and the creative students can flourish. Through the framing of this trait, it is noticed that creativity grows under positive encouragement (Wallace, 1986).

Vol. 1, No. 2, pp. $71-82$

Funding: This sully received nus Zaecifi financial support.

Article History:

Received: 13 March 2018

Revised: 26 October 2018

Accepted. 28 November 2018

( 2018 by the authors; licensee Academic Publishing Group 


\section{Collaborative Learning}

Collaborative, out of the classroom learning is known to park the enthusiasm of the student. However, when assessing collaborative learning with interior designers it is important to assess the level at which the collaboration occurs, whether it be on ground or on a digital platform and the involvement of online and elearning platforms. In a case-study approach research conducted by Sterling (2007) two interior design courses where integrated and were guided to lead a redesigning project. Through experiential leaning, students could leave the shelter of the academic holding and reach out of their comfort zone to achieve practical knowledge. Through the process, students could apply their knowledge and various other life stills, such as time management communication skills (Sterling, 2007).

A recent paper discussed the possible advantages of internationalizing interior design project through cross campus integration of multiple institutions through interior design students to create a unique collaboration. Allowing students to experience a sort of design exchange program in which they were working with students from six other design institutions from across Canada, USA and Mexico. The results created a unique global learning environment for the students involved. Future research on the depth of the impact of such a program on the students involved is needed in order to fully scale it Kucko, Prestwood, and Beacham (2005). When reviewing the possibility of blended learning applied on interior design courses, Afacan (2016), attempted to dispel previous misconceptions that interior design courses cannot be taught through an online medium due to the content. However, in Bilkent University, Turkey, 120 interior architecture students took part in an online learning experience through the theoretical interior design courses offered. Student's perceptions of the learning outcome were then surveyed and analyzed bringing forth the conclusion that teaching with both online and face-to-face in non-studio classes created an effective learning output and can contribute to the value of interior design educational teaching process (Afacan, 2016).

\subsection{Recommendations to Interior Design Programs}

Gürel (2010) looked at the importance of incorporating sustainable design practices with the interior design and architecture studio experience. Through qualitative research, student's results and surveying the graduated revealed student's awareness and responsible designing incorporated into their professional life. Findings also concluding that sustainability needs to be integrated into the interior design programs from an introductory level and throughout the entire curriculum.

A study conducted over 578 interior design students from 13 universities, to determine the relationship between student learning styles and their development of their visualization skills. In addition to determining in which year the design, students developed the greatest amount of visualization skills. The results provided that Converger and Assimilator where the learning style which presented the most positive results on the visualization tests. Results also presented that student's visualization skills developed the most in the second year of their interior design undergraduate program. This presenting the importance of incorporating teaching methods, which allow for student's development of visualization skills, which directly affect interior design student's output (Nussbaumer \& Guerin, 2000).

Experiential Learning Theory is tested in a study titled,_Learning Style of Design Students and the Relationship of Academic Performance and Gender in Design Education, 'where learning styles and gender are studied to determine their effects of design students through their three years of undergraduate learning. Findings displayed that the majority of the design students" learning styles were assimilating and converging groups. Males were found to outperform females in technology-based courses whereas females scored higher in more artistically driven courses. This bringing attention to the importance of integrating relevant teaching styles into the educational process of design courses (Demirbas \& Demirkan, 2007).

International Journal of Educational Studies Vol. 1, No. 2, pp. 71-82 2018 DOI: 10.53935/2641-533x.v1i2.75 DOI: 10.53935/2641-533x.v1i2.75
Corresponding Author: Isra Abu Zayed Funding: This study received no specific financial support. Article History:

Received: 13 March 2018 Revised: 26 October 2018 Accepted: 28 November 2018 Published: 21 December 2018 () 2018 by the authors; licensee Academic Publishing Group

\subsection{Interior Design Accreditation Bodies}

According to NASAD, National Association of Schools of Art and Design, which is one of the most highly regarded art and design accreditation bodies in the United States - first established in 1944, there is a specific curricula structure that is required in order for their accreditation body to acknowledge an interior design program. Curricula structure should adhere to the following guidelines:

- Studies in Interior design - 25-35\%

- Supportive courses in art, design and related technologies - 20-30\%

- Studies in art and design history - 10-15\% 


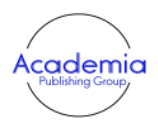

International Journal of Educational Studies Vol. 1, No. 2, pp. 71-82

2018

DOI: 10.53935/2641-533x.v1i2.75

DOI: 10.53935/2641-533x.v1 i2.75
"Corresponding Author: Isra Abu Zayed

Funding: This study received no specific

financial support.

Article History:

Received: 13 March 2018

Revised: 26 October 2018

Accepted: 28 November 2018

Published: 21 December 2018

(C) 2018 by the authors; licensee Academic Publishing Group
- General studies - 23-35\%

Overall - studies in the major area of art, design, visual art, histories and supportive courses should be at the bare minimum of $65 \%$ of the curriculum. In addition to the course distribution standards available, there is also essential competencies, experiences and opportunities section within the handbook, which lists the 14 key skills, which need to be acquired from within the degree (Annexure A). The skills and competencies range from the ability to apply basic principles of design to that of more advances application such as collaborations within and beyond the classroom to achieve real world experience (North American Standard Art Design 2017).

Another accreditation body which has a direct influence on the interior design program offered at a leading university is the Commission for Academic Accreditation (CAA), an accreditation body established by the Ministry of Higher Education and Scientific Research in the UAE. According to their standards and for required for program accreditation, specifically related to the curricula, there should be an appropriate sequencing of the courses offered. These courses can be divided into subcategories relating to major, general education and electives (Commision for Academic Acreditation, 2011). Although no specific information is shared in regards to interior design degree, the documents presents a clear and precise breakdown of the guidelines required for each course syllabi. The syllabi are a vital part of the process in order for it to clearly identify the significance and learning outcomes of each course (Commision for Academic Acreditation, 2011). When all the necessary criteria are included within the syllabi it becomes a clear document, which can be assessed by student, faculty and accreditation body as well (Annexure B).

\subsection{Renowned Interior Design Programs}

Another design institute is now emerging in the Dubai design industry. The Dubai Institute of Design and Innovation (DIDI) promises to provide the student with a design degree unlike anything, which already exists in the UAE and across the MENA region. Their innovative“ approach is presented through a four-year bachelors' of design degree. With very little information shared on their platforms the institute only boasts the claim that their curriculum will allow students to be in commend of their learning experience through maximizing flexibility. One unique feature, which appears to be present, is the university's collaboration with prominent universities: Massachusetts Institute of Technology (MIT) and Parsons School of Design (Dubai Institute of Design and Innovation, 2017).

On the international level, there are a few art and design schools, which are known in the design community to providing leading interior design degrees. Two of the top five are the Savannah College of Art and Design (SCAD), and Pratt Institute (Arch, 2016). The curricula of the interior design degree offered by Pratt Institute is one that is very structured (Annexure C). The courses are arranged in a semester basis with a total of 41 courses and 126 credits required to complete the program.

The courses are arranged over the course of eight semesters, which allow a total of four years to complete the degree. Seventy-five percent of the entire curriculum is in the area of the major, art and design studies, histories, supportive courses, which is 31 design related courses. The remaining 10 courses, which are approximately $25 \%$ of the total curriculum is allocated to general studies. This ratio of design courses to general studies is much higher than the required standard presented by NASAD, which has a $65 \%$ design course requirement.

At the Savannah College of Art and Design (SCAD), the total course of study within the curriculum 37 courses, with 12 of which are general courses (Annexure D). The design related courses add up to $67 \%$ of the degree. The percentage of the design courses offered is in line with that of the NASAD standard. The curriculum structure is flexible based on the student's own learning journey. Unlike that of the structures curricula found at the Pratt Institute.

\section{Results, Analysis and Discussion}

\subsection{Creativity}

In relation to the literature review, and the importance on which creativity is placed within the interior design program. The university's interior design program needs to first foster an environment of creativity in order to reach out to the students and encourage their creativity. Through the literature review it was determined that creativity can and will have an impact on a person's self-confidence and empowerment (Velthouse, 1990). This can be met through the development of a space which allows the student body to 
make their own choices, through this a sense of curiosity can be fostered, which is imperative to the design curriculum. This can be developed through allowing students to develop their own experiential design journey in the bachelors' program. As seen in SCAD (SCAD, 2017) interior design program, the program allows students to select their own journey and is not laid out through a rigid program. In parallel, this is what the Dubai Institute of Design and Innovation claims as their design teaching approach, fostering creativity through allowing the curriculum to be flexible (Dubai Institute of Design and Innovation, 2017). The university, located in Dubai UAE, has the advantage of being a multicultural environment reflecting the society in which it is present. Through this multicultural setting the improvement of student output, which was stating by Tadmor et al., can be achieved. Through diversity of the student body, stronger and more creative content is produces (2012).

\subsection{Collaborative Learning}

Collaborative learning encourages the students to reach out of their comfort zone and apply their attained knowledge as well as other life skills into their projects. Sterling (2007). Collaborative learning, as reviewed through the literature review is a variety of ways in which students are encouraged to work together, in an unorthodox learning environment, results in heightened learning experience. Through these project-based collaborations, students are encouraged to lead in order to achieve results. Technological involvement allows the collaboration to be international as seen with Kucko et al. (2005). Through this international exposure, students are exposed to a more international experience, which can lead to Tadmor, Satterstrom, Jang, and Polzer (2012) findings, which support the findings that multicultural leaning environments produce output that is more creative. Although the university does take part in interior design competitions and initiatives from around the UAE, it is also vital for the development of the student body for there to be international collaborations for students to be able to design and work with peers from other universities. These type of virtual collaborations can add growth to the flexible learning environment as well as encourage senior students to attain real world expose of the interior design collaboration and industry standards Kucko et al. (2005).

\subsection{Recommendations to Interior Design Programs}

Gürel (2010),highlighted the importance of incorporated sustainable design practices into the curriculum of the interior design programs. Although sustainability is incorporated as a topic within the interior design courses at the selected university, the topic has become of great importance that it requires more integration into the program. A possible recommendation of this is to have a sustainable design course offered as a core course. This can be of great value to the student body and their future interior design careers. An important teaching methodology to apply for the interior design program is both the converger and the assimilator. As converging and assimilating are a good basis for encouraging students to develop their core art and design skills. Through the beginning of the interior design students require a guided discovery learning approach in order to develop the confidence required for them to progress in their undergraduate journey. Apply the converging and assimilating methodologies can help develop the students' visualization skills, especially during the core and foundation courses of the bachelor's degree (Nussbaumer \& Guerin, 2000).

\subsection{Standard Benchmarking}

The interior design program at the university offers 126 credits hours within the curriculum, this allowing for 40 courses (Annexure E). The courses are divided in 4 distinct categories: general courses, core or foundation courses, specialization courses and electives. Of the 40 courses, 11 are general courses, 3 are elective courses, 9 are core courses and 17 are specialization courses. When assessing the total of designoriented courses available within the program and benchmarking them with the NASAD standards it is noted that the core and specialization courses add us to $65 \%$ of the total courses offered in the curriculum. Although this meets the standard of the NASAD course, distribution it still falls on the bear minimum of the requirements. When comparing the NASAD essential competencies, experiences and opportunities with the curriculum offered at the university's interior design program, we find that the course learning outcomes of the courses meet the NASAD requirements (Annexure F).

Therefore, when benchmarking university's Interior design program with that of the NASAD standard a recommendation is brought forth. Related to the increase of design related courses in order to increase the

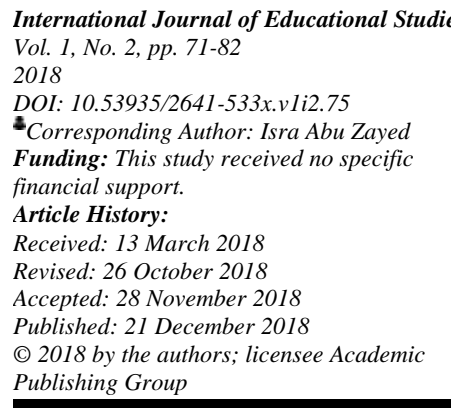


minimum amount of design interaction, which the students gain throughout their undergraduate experience from the minimum amount of $65 \%$. In order to achieve these courses related to the interior design program must be added to the program. This gap can be filled with a sustainable design course to be offered as a core design course.

\section{Results}

Through the literature review and data analysis, the following seven key findings are recommendations are made for the interior design program at the university:

- Encouraging a creative and empowering learning environment through allowing a flexible curriculum, which allows students to develop their own experiential design journey in the bachelors ' program.

- Incorporate collaborative learning allowing students to apply their attained knowledge as well as other life skills into their projects

- International collaborations for student projects allowing students to design and work with peers from other universities.

- Apply the converging and assimilating methodologies can help develop the students' visualization skills, especially during the core and foundation courses of the bachelor's degree

- Increase of design related courses to increase the minimum amount of design interaction, which the students gain throughout their undergraduate experience from the minimum amount of $65 \%$.

- Recommendation for offering sustainable design as a design core course

\section{Conclusion}

The university is a relatively new educational institute in Dubai and the region. With only eight years of presence in the academic industry, the university still has much growth and development to gain. For it to be set apart from the other educational institutes in the region, it must be able to present unique and innovative program and curricula's. With recent studies in Dubai, highlighting the projected growth of the design sector in the region there is immense potential for growth and development. The university can seize this opportunity as a challenge to capitalize on the growth in the design sector. With 26 other educational institutes in the region that offer a bachelor's degree in interior design the university will need to develop its interior design program into one that is unique and specialized in the region.

Upon review of the most recent literature on the matter of interior design, curriculum developments there were three categories in total, which presented relevant findings. The first was creativity: the ability to establish a learning environment that fosters creativity in order to ensure the highest quality of student output. Creativity is needed in order to ensure that the program and curricula can be administrated in a successful manner. In order to foster this creativity students are to be given a sense of choice and flexibility in their learning journey, as well as being exposed a variety of people through multicultural learning environment. The second category was collaborative learning: like creativity collaborative learning in and outside of the classroom proved a great tool for student engagement. Students learning through working on design projects for the community or through international collaborations across countries and educational institutes. These types of collaborations increase student interest, motivation and encourage a more creative output. The third literature category reviewed was that related to course recommendations in the field of interior design. It was related to the types of courses and course delivery, which are proving to be the most impactful on the students of interior design programs. Sustainability as a course topic as well as assimilation and convergence as teaching methodologies. This was then followed by a look at the accreditation bodies most relevant to the interior design program. One being the NASAD and the other being a regional accreditation body, CAA. The final category in the literature review was a look at the leading design schools and analyze some of the unique features in their curriculum and program offering.

Through the literature review, an analysis of the findings and comparison to the existing interior design program at the university was made. This process resulted in three sets of conclusions:

- The first was recommendation for improvement of the learning environment and the collaborative work both within the institution and internationally.

- The second was recommendations made based on the findings of the most effective teaching methodology to enhance the student's visualization skills through converging and assimilating methodologies. 
- The third were possible addition to the course program in order to meet both the NASAD competencies, enhance the percentage of design course output in the curriculum and reflect some of the findings related to the importance of incorporating sustainable design within interior design program.

As the current interior design program at the university has already established accreditation from the $\mathrm{CAA}$, it meets the basic requirements of an interior design undergraduate program. However, in order for the program to align itself with as a leader and innovator in the design industry in the UAE then there needs to be innovative practices implemented within it. The NASAD is the leading body of accreditation for arts and design programs. Therefore, it was utilized as a benchmarking for the interior design program at the selected university. Future recommendations for the study is to assess the up and coming Dubai Institute of Design and Innovation. As the institute is a self-proclaimed innovative institute it would be of interest to the design industry to discover, the means at which they plan to develop their programs, curriculums and teaching methods. The Institute is set to open in 2019 but already has the back of the Dubai Fashion and Design Council and is located in the heard of Dubai Design District, which is additional to its claim of being a unique academic institute in the region solely focused on art and design innovation.

\section{References}

Afacan, Y. (2016). Exploring the effectiveness of blended learning in interior design education. Innovations in Education and Teaching International, 53(5), 508-518.Available at: https://doi.org/10.1080/14703297.2015.1015595.

American Society of Interior Designers. (2016). Interior design-the state of the industry. Retrieved from https://www.asid.org/resources/resources/view/resource-center/123.

Arch. (2016). Top 10 interior design schools around the world. Retrieved from http://www.arch2o.com/top-10-interior-design-schoolsaround-world/.

Association of Professional Interior Designers. (2017). World interiors day. Retrieved from http://www.apid.ae/world-interiors-day$\underline{2016}$.

Commision for Academic Acreditation. (2011). CAA Handbook. Retrieved from https://www.caa.ae/caa/images/standards2011.pdf.

Demirbas, O. O., \& Demirkan, H. (2007). Learning styles of design students and the relationship of academic performance and gender in design education. Learning and Instruction, 17(3), 345-359.Available at: https://doi.org/10.1016/j.learninstruc.2007.02.007.

Dubai Institute of Design and Innovation. (2017). Programs.

Gürel, M. Ö. (2010). Explorations in teaching sustainable design: A studio experience in interior design/architecture. International Journal of Art \& Design Education, 29(2), 184-199.Available at: https://doi.org/10.1111/j.1476-8070.2010.01649.x.

Kucko, J., Prestwood, L., \& Beacham, C. (2005). The consortium for design education: A model for internationalizing interior design programs. Journal of Interior Design, 31(1), 25-37.Available at: https://doi.org/10.1111/j.1939-1668.2006.tb00415.x.

Nussbaumer, L. L., \& Guerin, D. A. (2000). The relationship between learning styles and visualization skills among interior design students. Journal of Interior Design, 26(2), 1-15.Available at: https://doi.org/10.1111/j.1939-1668.2000.tb00355.x.

SCAD. (2017). Programs. Retrieved from https://www.scad.edu.

Sterling, M. (2007). Service-learning and interior design: A case study. Journal of Experiential Education, 29(3), 331-343.Available at: https://doi.org/10.1177/105382590702900305.

Tadmor, C. T., Satterstrom, P., Jang, S., \& Polzer, J. T. (2012). Beyond individual creativity: The superadditive benefits of multicultural experience for collective creativity in culturally diverse teams. Journal of Cross-Cultural Psychology, 43(3), 384-392.Available at: https://doi.org/10.1177/0022022111435259.

Velthouse, B. A. (1990). Creativity and empowerment: A complementary relationship. Review of Business, 12(2), 13-19.

Wallace, B. (1986). Creativity: Some definitions: The creative personality; the creative process; the creative classroom. Gifted Education International, 4(2), 68-73.Available at: https://doi.org/10.1177/026142948600400202.

\section{Annexure A}

Nasad Essential Competencies, Experiences and Opporutnties

a. Ability to conceive of and design for interior spaces, incorporating and integrating the knowledge and skills listed in 3.b. through j. below.

b. Understanding of the basic principles and applications of design and color in two and three dimensions, particularly with regard to human response and behavior. Design principles include, but are not limited to, an understanding of basic visual elements, principles of organization and expression, and design problem solving.

Vol. 1, No. 2, pp. 71-82

2018

DOI: $10.53935 / 2641-533 x . v 1 i 2.75$

DOI: 10.53935/2641-533x.v1i2.75
"Corresponding Author: Isra Abu Zayed

Funding: This study received no specific financial support.

Article History:

Received: 13 March 2018

Revised: 26 October 2018

Accepted: 28 November 2018

Published: 21 December 2018

(C) 2018 by the authors; licensee Academic

Publishing Group

c. Ability to apply design and color principles in a wide variety of residential and nonresidential projects. This requires an in-depth knowledge of the aesthetic and functional properties of NASAD Handbook 2015-16 124 


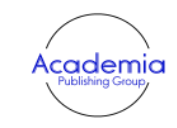

International Journal of Educational Studies Vol. 1, No. 2, pp. 71-82

2018

DOI: 10.53935/2641-533x.v1i2.75

DOI: 10.53935/2641-533x.v1i2.75
"Corresponding Author: Isra Abu Zayed Funding: This study received no specific financial support.

Article History

Received: 13 March 2018

Revised: 26 October 2018

Accepted: 28 November 2018

Published: 21 December 2018

(C) 2018 by the authors; licensee Academic Publishing Group
X.F. structure and surface, space and scale, materials, furniture, artifacts, textiles, lighting, acoustics, heating and cooling systems, air quality systems, and the ability to research and solve problems creatively in ways that pertain to the function, quality, and effect of specific interior programs.

d. Understanding of the technical issues of human factors and basic elements of human behavior, including areas such as programming, environmental control systems, anthropometrics, ergonomics, proxemics, wayfinding, sustainability, universal design, and design for the physically/mentally challenged. In making design decisions, the ability to integrate human behavior and human-factor considerations with project goals and design elements is essential.

e. Knowledge of the technical aspects of construction and building systems, and energy conservation, as well as working knowledge of applicable legal codes, contract documents, specifications protocols, schedules, and regulations related to construction, environmental systems, accessibility, and human health and safety, and the ability to apply such knowledge appropriately in specific design projects.

f. Ability to hear, understand, and communicate to the broad range of professionals and clients involved or potentially involved the concepts and requirements of interior design projects. Such communication involves verbal, written and representational media in both two and three dimensions and encompasses a range from initial sketch to finished design. Capabilities with technical tools, conventions of rendering and representation, global measuring systems, and systems of projection, including perspective, are essential. Competence with technologies applicable to interior design is also essential. The ability to work on teams is essential.

g. Functional knowledge of production elements such as installation procedures, project management, schedules, and specification of materials and equipment.

h. Acquisition of collaborative skills and the ability to work effectively in interdisciplinary or multidisciplinary teams.

i. Functional knowledge of the history of art, architecture, decorative arts, and interior design, including but not limited to the influences of work and ideas on the evolution of interior design practice.

j. Functional knowledge of professional design practices and processes, including but not limited to professional and ethical behaviors and intellectual property issues such as patents, trademarks, and copyrights.

k. Functional knowledge of basic business practices including, but not limited to entrepreneurship, marketing, accounting, and manufacturing; and basic practices associated with the overall business of interior design such as ethics, intellectual property, labor issues, and decisions associated with ecological and social responsibility and sustainability.

1. The ability to gather information, conduct research, and apply research and analysis to design projects. Familiarity with research theories and methodologies related to or concerned with interior design is essential.

m. Experience in applying design knowledge and skills beyond the classroom is essential. Opportunities for field research and experience, internships, collaborative programs with professional and industry groups, and international experiences are strongly recommended. Such opportunities to become oriented to the working profession should be supported through strong advising.

n. Experience with a variety of professional practices and exposure to numerous points of view in historic and contemporary interior design.

\section{Annexure B}

Commission for Academic Accreditation Ministry of Higher Education and Scientific Research UAE. Criteria Required for Program accreditation

3.3 The Curricula. The curricula: 3.3.1 comprise an appropriate sequence and mix of courses (such as major, general education, and electives; introductory and advanced with prerequisites); 3.3 .2 include a number of credit hours consistent with international practice in the discipline and level of award; 3.3 .3 are upto-date in terms of content and practice; 3.3.4 are clearly described and published in the catalog and other relevant publications; 3.3.5 comprise a defined amount and quality of work of sufficient rigor.Syllabus Guidelines For each course offered:

The institution provides a descriptive syllabus, which is a comprehensive document containing sufficient information to ensure that: 
1. Those involved in curriculum development understand any pre-requisites or co-requisites and the learning outcomes of the course;

2. External reviewers understand the course's contribution to the program and connection to other courses in the curriculum;

3. Students who take the course understand what they need to have achieved in order to take the course, what will be expected of them during the course, and what they will have achieved having taken the course;

4. Any suitably qualified instructor could deliver the course satisfactorily within the curriculum;

5. Sufficient information on the course is available for the purposes of course and program review (program effectiveness). Each course description must include the following information, along with anything else the institution chooses to add:

1. Course title and course code/number, credit hours, pre-requisites, co-requisites (if any);

2. Name, contact information and office hours of the current instructor;

3. Brief course description;

4. Intended learning outcomes of the course;

5. Course topics and contents on a week-by-week basis;

6. out-of-class assignments with due dates for submission;

7. Methods and dates of student evaluation, including the relative weight of various assessment methods in determining the course grade;

8. Teaching and learning methodologies;

9. Course texts, recommended reading, instructional material and resources.

\section{Annexure C}

Interior Design Program at Pratt Institute

B.F.A. in Interior Design

Semester 1

FDC-140 Visualization/Representation 3 FDC-150 Space, Form, Process 3 FDC-160 Light, Color, Design Lab 3 HA-111 Themes in Art and Culture I 3 HMS-101A Literary and Critical Studies I 3

Credit subtotal 15

Semester 2

FDC-141 Visualization/Representation/Concept 3 FDC-161 Light, Color, Design Studio 3 FDC-180 New Form/Time and Movement 3 HA-112 Themes in Art and Culture II 3

Social Science -Globall Core Elective 3 Credit subtotal 15

Semester 3

INT-201 Design I 3 INT-233 Language of Drawing I 3 INT-217 Assemblies and Environments 3 HD-364 History of Interior Design 3

Social Science -Thinkingl Core Elective 3 Credit subtotal 15

Semester 4

INT-202 Design II 3 INT-234 Language of Drawing II 3 INT-218 Color Materials Lighting 3 HMS-201A Literary and Critical Studies II 3

Math/Science Core Elective 3 Credit subtotal 15

Semester 5

INT-301 Design III 3

325.INT-325 Emergent Platforms 3 326.INT-326 Materials Method Meaning 3

Departmental Elective 3 History of Art and Design Elective 3 Liberal Arts Post-Core Elective 3 Credit subtotal

18

Semester 6

INT-302 Design IV 3 INT-342 Time Culture Context 3

Pratt Integrative Course 3 Departmental Elective 3 Liberal Arts Post-Core Elective 3 Liberal Arts Post-Core Elective (300/400 level) 3 Credit subtotal 18

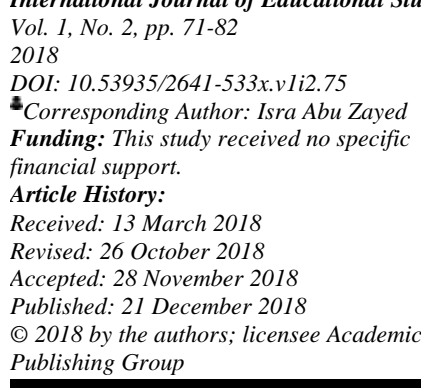


Semester 7

INT-401 Design V 3 INT-405 Design Research Strategies 3 INT-419 The Working Set 3 Departmental Elective 3 Liberal Arts Post-Core Elective (300/400 level) 3 Credit subtotal 15

Semester 8

INT-402 Design VI Thesis 3 INT-441 Positioning Practice Portfolio 3

Liberal Arts Post-Core Elective (300/400 level) 3 All Institute Elective 6 Credit subtotal 15 Total credits required 126.

\section{Annexure D}

Interior Design Program at Scad

B.F.A. in interior design Foundation studies: 35 hours

1 DRAW 100 Drawing I: Form and Space

2 DRAW 101 Drawing II: Composition and Media

3 DRAW 115 Graphics for the Building Arts

4 DSGN 100 Design I: Elements and Organization

5 DSGN 101 Color: Theory and Application

6 DSGN 102 Design II: 3-D Form in Space

7 - Studio elective General education: 55 hours

1 ARLH 206 Modern Architecture I: 1750-1900

2 ARLH 208 Modern Architecture II: 1900-Present

3 ARLH 211 Survey of World Architecture and Urbanism*

4 ARLH 363 World Vernacular Architecture*

5 ARTH 100 Survey of Western Art I

6 ARTH 110 Survey of Western Art II

7 COMM 105 Speaking of Ideas

8 ENGL 123 Composition

9 - ENGL elective

10 - General education elective $\dagger$

11 - Mathematics/natural sciences elective $\dagger+12$ - Social/behavioral sciences elective $\dagger$ Major curriculum: 80 hours

- ELDS 225 Electronic Design I: Digital Communication for the Building Arts

- INDS 101 Introduction to Interior Design

- INDS 102 Form, Space and Order

- INDS 110 Interior Design Studio I: Exploring People and Space

- INDS 204 Rendering for the Interior

- INDS 209 Interior Materials

- INDS 210 Interior Design Studio II: Specialized Interior Environments

- INDS 211 History of Interior Design

- INDS 220 Building Construction and Systems for the Interior

- INDS 302 Lighting for the Interior

- INDS 320 Interior Design Studio III: Documentation and Communication

- INDS 350 Interior Design Studio IV: Collaborative Practice in Design INDS 413 Professional Practice in Interior Design.

- INDS 470 Interior Design Studio V: Capstone I - Design Thinking for Innovation

- INDS 480 Interior Design Studio VI: Capstone II - Design Development and Communication International Journal of
Vol. 1, No. 2, pp. $71-82$

$$
\begin{aligned}
& \text { Vol. } 1 \text {, } \\
& \text { 2018 } \\
& \text { DOI: } 10.5
\end{aligned}
$$

DOI: $10.53935 / 2641-533 x \cdot v 1 i 2.75$

DOI: $10.53935 / 2641-533 x . v 1$ i2.75
"Corresponding Author: Isra Abu Zayed

Corresponding Author: Isra Abu Zayed
Funding: This study received no specific financial support.

Article History:
Received: 13 March 2018

Revised: 26 October 2018

Accepted: 28 November 2018

Published: 21 December 2018

(C) 2018 by the authors; licensee Academic Publishing Group 


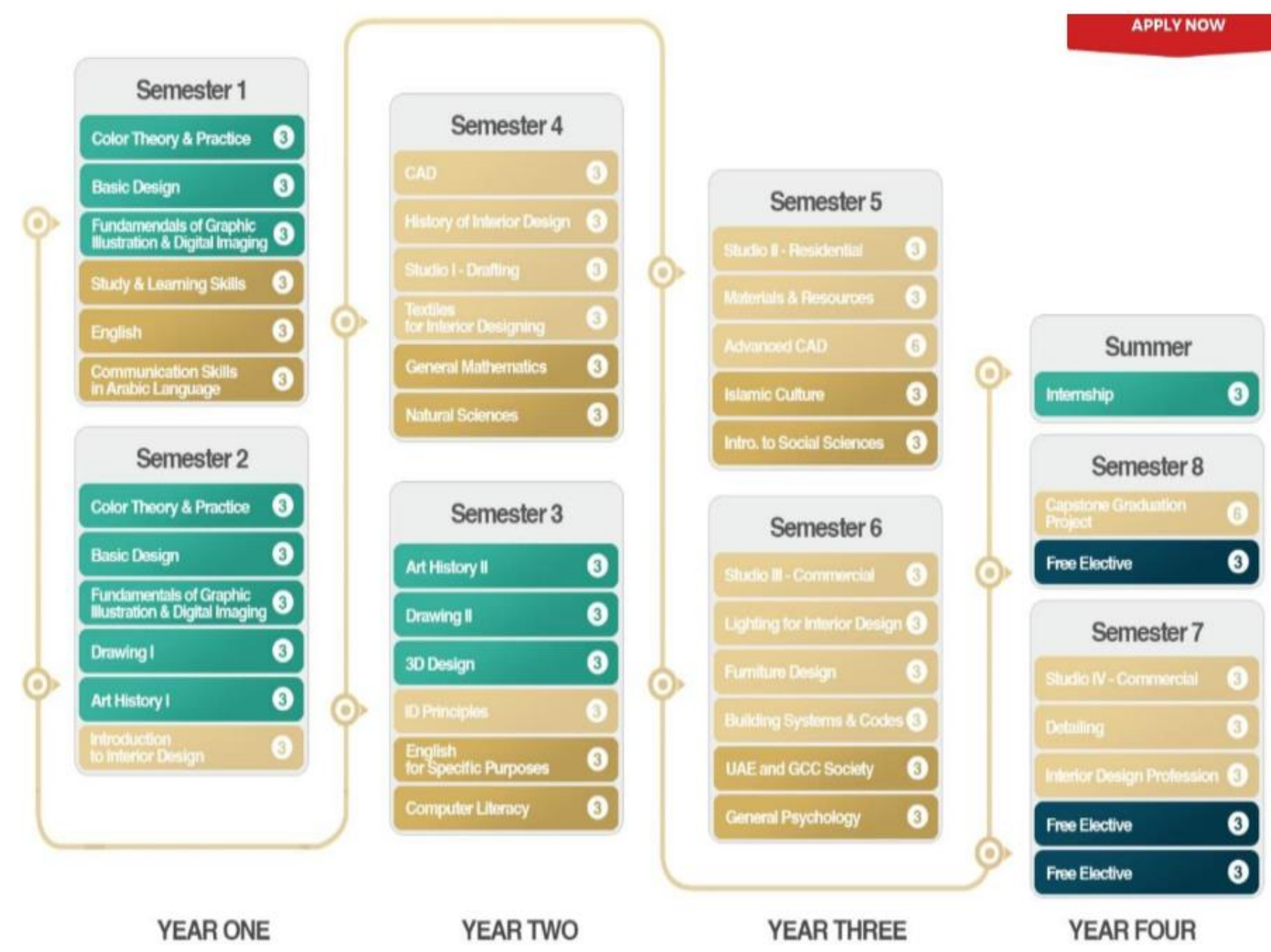

Academia

International Journal of Educational Studies

Vol. 1, No. 2, pp. 71-82

2018

DOI: $10.53935 / 2641-533 x$ vli2.75

"Corresponding Author: Isra Abu Zayed

Funding: This study received no specific

financial support.

Article History:

Received: 13 March 2018

Revised: 26 October 2018

Accepted: 28 November 2018

Published: 21 December 2018

(C) 2018 by the authors; licensee Academic Publishing Group

81 


\section{Annexure F}

Comparing the NASAD Essential Competencies, Experiences and Opportunities to the Interior Design Curriculum offered.

\begin{tabular}{|c|c|c|}
\hline $\begin{array}{l}\text { NASAD Essential Competencies, Experiences and } \\
\text { Opportunities }\end{array}$ & $\begin{array}{l}\text { Interior Design } \\
\text { Specialization courses } \\
\text { which CLOs meet the } \\
\text { NASAD Essential } \\
\text { Competencies, } \\
\text { Experiences and } \\
\text { Opportunities }\end{array}$ & $\begin{array}{l}\text { Does the course } \\
\text { offered cover all of } \\
\text { the competencies } \\
\text { accurately? }\end{array}$ \\
\hline $\begin{array}{l}\text { a. Ability to conceive of and design for interior spaces, } \\
\text { incorporating and integrating the knowledge and skills } \\
\text { listed in 3.b. through j. below. }\end{array}$ & $\begin{array}{ll}\text { - } & \text { Introduction to } \\
\text { - } & \text { Interior Design } \\
\text { - } & \text { ID Principles } \\
\text { - } & \text { Studio } 1,2,3,4\end{array}$ & Yes \\
\hline $\begin{array}{l}\text { b. Understanding of the basic principles and } \\
\text { applications of design and color in two and three } \\
\text { dimensions, particularly with regard to human response } \\
\text { and behavior. Design principles include, but are not } \\
\text { limited to, an understanding of basic visual elements, } \\
\text { principles of organization and expression, and design } \\
\text { problem solving. }\end{array}$ & $\begin{array}{ll}\text { - } & \text { Color Theory } \\
\text { - } & \text { Introduction to } \\
\text { Interior Design } \\
\text { - } & \text { ID Principles } \\
\text { - } & \text { Studio } 1,2,3,4\end{array}$ & Yes \\
\hline $\begin{array}{l}\text { c. Ability to apply design and color principles in a wide } \\
\text { variety of residential and nonresidential projects. This } \\
\text { requires an in-depth knowledge of the aesthetic and } \\
\text { functional properties of NASAD Handbook 2015-16 } \\
124 \\
\text { X.F. structure and surface, space and scale, materials, } \\
\text { furniture, artifacts, textiles, lighting, acoustics, heating } \\
\text { and cooling systems, air quality systems, and the ability } \\
\text { to research and solve problems creatively in ways that } \\
\text { pertain to the function, quality, and effect of specific } \\
\text { interior programs. }\end{array}$ & \begin{tabular}{ll} 
- & \multicolumn{2}{l}{ Color Theory } \\
- Textiles for \\
Interiors \\
- Materials and \\
Resources \\
- Lighting Design \\
- Building \\
Systems and \\
Codes
\end{tabular} & Yes \\
\hline
\end{tabular}

